\title{
STRONG MOTION SEISMOLOGY
}

\author{
D. E. Hudson*
}

\begin{abstract}
Strong motion accelerographs and data processing systems for the measurement of strong ground motion of damaging earthquakes are described with some comments on future developments. Some information is given on the earthquakes and instrumentation sites for which important records have been obtained. Studies of the areal distribution of ground motions during earthquakes are discussed in terms of transmission path effects. Some speculations are advanced concerning the establishment of limiting values of earthọuake ground motions.
\end{abstract}

\section{INTRODUCTION}

In the pre-instrumental era of earthquake engineering, much was learned about the effects of earthquakes upon structures by a careful study of the damage caused by large earthquakes, and in this way many of the basic principles of earthquake engineering became known in a qualitative way. A more exact study of such problems became possible only when the actual motions of the ground during strong earthquakes were directly measured in the early 1930's. Since that time and particularly since the late 1960's, a rapid growth in the deployment of special instrumentation to record strong ground motions throughout the seismic regions of the world has resulted in the accumulation of a large data bank of useful records. These records have provided the fundamental information for a new science of strona motion seismology and for the development of increasingly accurate quantitative methods in earthquake engineering. Until very recently in the history of seismology the attention of geophysicists has been directed almost entirely to far-field ohenomena involving measurements of very small ground motions at large distances from earthquake sources. Development of the required instrumentation and the analysis of data for damaging earthquake ground motions have been carried out by earthquake engineers. Recently seismologists have become more interested in such subjects as earthquake source mechanisms which also require measurements of strong ground motions near the source, so a fruitful collaboration between seismologists and earthquake engineers in the problems of strong motion seismolooy is beginning to develop.

The purposes of the present survey are (1) To briefly describe the instruments required for such investigations and the networks and data processing facilities that are presently available, (2) To summarize the characteristics of the recorded earthquakes and of the instrumentation sites and to evaluate the adequacy of the data base, (3) To outline some significant studies which

* California Institute of Technology, Pasadena, CA 91125; Visiting Erskine Fellow, Department of Civil Engineerina, University of Canterbury, Christchurch. have been based on such data, and (4) To suggest some lines of development for future investigations.

\section{STRONG MOTION INSTRUMENTATION}

Because instrumentation to measure strong ground motion is at present in a rapidiy developing stage with many current proposals for new types of instruments and new approaches to network design, it will be of importance to give some background detail. To measure the destructive ground motions associated with damaging earthquakes, the engineer requires an insensitive instrument which will remain on-scale during the largest ground motions likely to be encountered and which will faithfully record over the whole frequency range of structural importance. This has been accomplished by the development of the strong motion accelerograph, which recoras accelerations up to one $g$ or over with a resolution of the order of $0.001 \mathrm{~g}$ and $\mathrm{a}$ frequency range of $0.06 \mathrm{~Hz}$ to $25 \mathrm{~Hz}$. There are now some 5,000 instruments of this kind distributed unevenly throughout the seismic regions of the world - approximately 1,500 in the United States, 1,000 in Japan, and several hundred each in New Zealand, Yuooslavia, Iran, Mexico, etc. New Zealand has contributed in a major way to the development of such instrumentation through the MO 2 accelerograph, which in the 1960's was the first relatively low-cost instrument which could be readily installed in the large numbers necessary for adequate coverage.

Rough estimates of the expenses of maintaining networks indicate that the direct cost of each useful strong motion accelerogram is of the order of $\$ 10,000$ which suggests that a considerable data processing effort is justified in the interest of acquiring the maximum amount of information from each record. The data processing system should be thought of as an integral part of the whole accelerograph network and is in fact the element for which the most sionificant improrements in information collection are likely to be realised. The most important advance in data processing made in recent years is the routine introduction of digital filtering. This filtering technique based on running weighted averages is particularly well suited to digital 
computations and has made it possible to carry out accelerogram integrations and transducer corrections over a considerably wider frequency range than had been possible by other techniques. Not only can new records be routinely processed to a higher order of accuracy, but it is feasible to reprocess some of the old photographic paper records dating back to the 1930's and to recover considerably more information from them than had originally been thought possible.

The existing field accelerographs produce records in the form of an analog photographic trace on a $35 \mathrm{~mm}$ or $70 \mathrm{~mm}$ film. For detailed analysis of the information, the analog record is digitized using a semi-automatic machine which combines handeye setting of a cross hair on the analog trace with automatic readout and recording of time and acceleration coordinates on punched cards or magnetic tape. Currently under development is a completely automatic type scanning digitizer which will require operator intervention only for those portions of the record which involve ambiguities or defects. A critical advantage of the current optical-photographic analog recorder plus automatic diqitization is that it permits the widely dispersed field elements to be of a very simple form while the more complex digitization apparatus can remain in the laboratory. Thus the special advantages of both analog and digital systems are combined in an optimum way for this particular application.

A considerable effort is now being made to develop a digital field accelerograph which would directly produce the basic record on computer-compatible digital magnetic tape. This would of course eliminate the need for the relatively laborious semi-automatic digitization of the analog photographic traces, at a cost of a more complex installation in the field. The desirability of such digital field systems depends-upon the extent to which rapid digitization of records is believed to be important. In my opinion digitization requirements do not represent a decisive disadvantage for the film recording system for the following reasons. First, a large amount of information of immediate practical importance is quickly available on the analog record without digitization or further processing. practical decisions which must be made promptly after an earthquake, such as the need to evacuate a damaged structure or to empty a reservoir, can be made from the analog record and are not likely to be significantly modified by additional data processing. In fact, the analog film record has many advantaqes over the digital tape for this purpose since it can be developed with facilities readily available almost anywhere in the world and the significant features can be quickly determined by persons with a minimum of special training or experience. secondly, even though a large earthquake should occur near a dense accelerograph network it is not likely that there will be more than a few dozen key records requiring immediate attention. For the San Fernando, California, earthquake, for example, although there were a total of 241 records almost all of which proved to be of ultimate interest, there were only a half dozen or so near the epicenter of such special interest that rapid processing was of importance.
Recent advances in digital instrumentation and in integrated circuit technology would seem to make it feasible to produce a practicable diqital field accelerograph, although the cost of current prototypes having essentially the same overall specifications of accuracy, dynamic range and frequency response is about twice that of the standard analog photographic accelerograph. An additional disadvantage of currently available digital accelerographs is the somewhat larger standby power requirements which reduces the non-external power operating life by a significant amount. An advantage of the digital system is the possibility of providing a short memory to recover the earliest portion of the triggering ground motion. In view of the relatively quick action of modern vertical triggers, the memory is probably justified only if the additional complexity and power requirement does not compromise the field reliability of the accelerograph. Digital accelerographs would also be somewhat more dependent on laboratory-based playback equipment, since it will usually be essential for preliminary inspection and analysis to have an analog record. It is also likely that more elaborate field test equipment will be required with a correspondingly higher level of training of maintenance personnel. The long range potential of such digital systems, however, is so attractive that an extended period of careful field testing and evaluation is certainly justifiable. The first practical applications of completely digital systems will probably be in large special instrument arrays rather than in the widely dispersed individual stations which have characterized strong motion studies in the past.

The overall capabilities of any measurement system can be measured by the relationship between noise characteristics which limit the ability of the system to produce low level analyzable records and the size of the signal to be measured. As an example of the current state of the art, the performance of the instrumentation and data processing system used in the present United States strong motion accelerograph network is summarized in Fig. 1. Since frequency analysis of records is a frequent end product, the instrument signal level can be conveniently represented by the Fourier amplitude spectra which can be directly compared with the Fourier spectra of the noise in the signal. For practical purposes this is equivalent to a comparison of the earthquake undamped velocity response spectra with the response spectra of the background noise. From the left-hand portion of Fig. I it will be seen that with the present system earthquakes of magnitude much less than $M=4$ will involve ground motions even in the epicentral regions so small that they will not be distinguishable on the record from noise. From the right-hand portion of Fig. I it will be seen that for an earthquake of given size, in this case $\mathrm{M}=6.5$, the ground motions will drop below measurable size at distances of the order of $100 \mathrm{~km}$ to $200 \mathrm{~km}$. In this way the capability of the system to adequately sample a given area can be ascertained and an optimum network design can be accomplished.

THE STRONG MOTION ACCELEROGRAM DATA BANK 
available for the study of strong ground motion, the contents of the Caltech data bank of uniformly processed records will be briefly described. This data set comprises 381 three-component accelerograms, 187 of which are ground sites, the rest being from upper locations on structures. The ground site records are usually from the basements of buildings, and it has been ascer-ained that over most of the frequency range of structural interest these basement records with a few exceptions are good. estimates of free-field ground motion. The site conditions can be roughly classified as about 60 percent soft-alluvium, 10 percent hard-rock, and 30 percent intermediate. In the present state of limited knowledge as to the details of site conditions, this is about as fine a classification as is feasible. An important task for the future is to collect more detailed information on site conditions and local geology for instrument sites for which important accelerograms have been obtained. The total number of earthquakes represented in the data set is 57, ranging in size from $M=3$ to a maximum of $M=7.7$. The maximum number of records at one site is 16 at El Centro, California; the maximum number of records from one earthquake is 241 for the 1971 San Fernando earthquake, of which 98 are ground motion records.

The data bank described above is supplemented in a very important way by a number of more recent earthquakes, plus several dozen strong motion records from other countries which have been obtained with similar instrumentation. There is also a large collection of records from the New Zealand and Japanese networks, but only a few of these accelerograms are of damaoing ground motion. In most cases the recording sites have either been distant from the earthquake or the earthquake has been a relat:vely small one.

\section{NEAR FIELD ACCELEROGRAMS}

of the more than 1,000 useful accelerograms obtained since the first record from the Long Beach, California, earthquake of 1933, most have been at considerable distances from relatively small earthquakes. Only a few dozen have been recorded at distances from points of large seismic energy release as small as the source dimensions of the earthquake. These may be called near field measurements, and they describe the most severe ground motions and supply the most information about earthquake mechanisms.

Figure 2 shows a collection recently made of all available near field accelerograms, giving one horizontal component of motion. All have been drawn to the same amplitude and time scales. It will be noted that there are striking differences in the size and appearance of the records, which suggests that the visual character of the accelerograms may be an important indicator of significant aspects of the earthquake which may be difficult to describe in a quantitative way through such parameters as peak values, durations, or spectral properties. This is another aspect of the well known problem that no simple set of parameters or combinations thereof seem to correlate very well with the general impression of the damage potential of the event. This diversity of visual impression also emphasizes some of the problems of defining a typical earthquake.

It will be noted that the largest earthquake in Fia. 2 is the $M=7.1$

Olympia, Washington, earthquake. The largest earthquake for which any strong motion record exists is the $\mathrm{M}=7.7$ Kern County, California, event, recorded at a distance of $60 \mathrm{~km}$. We have no accelerograms for such great earthquakes as the 1906 San Francisco, the 1923 Tokyo, the 1960 Chile, the 1964 Alaska, or the recent devastating major shocks in China. This is one reason why a good deal of theoretical work is needed to extrapolate available records to other situations. A hopeful factor is the present belief that great earthquakes involve very large generating areas, so that much of the energy release must come from points far away from a given point. A great earthquake in fact appears to be a sequence in time and space of the kinds of smaller events seen in $\mathrm{Fig} .2$. If this is the case, the maximum amplitudes of ground motion at a particular point may not be bigger for a great earthquake than for a smaller shock, but the duration of the ground motion would be longer. This points up the importance of duration for engineering studies and means that additional investiations are required of the way structures deteriorate during extended applications of cycles of alternating loads.

It would be expected that a study of such near field records would throw some light on the important problem of establishing upper bounds for earthquake ground motion. It is usually supposed that the strength properties of the earth's crust impose some limits to the amplitude of ground shaking, but ideas as to what these limits might be are being gradually scaled upwards as more records become available. For some years the 1940 El Centro earthquake was the most damaging earthquake ground motion that had been measured, and for a time the acceleration level of about one-third $g$ was thought to be near the upper limit, at least for the geologic conditions present there. Then the 1966 Parkfield earthquake came along with a fifty percent g acceleration and did very little damage. In 1967 the Koyna earthquake in India with a two-thirds $g$ acceleration for a time held the record. The present champion is of course the 1971 San Fernando earthquake with one and onequarter $\mathrm{g}$. Since then there have been a number of small earthquakes having acceleration peaks as high as three-fourths $\mathrm{g}$. It is of course now well understood that the amplitudes of the high frequency acceleration peaks may depend greatly on the characteristics of the recording instruments, and that these high frequency peak accelerations do not necessarily bear any relationship to the damage potential of the earthquake for most engineering structures.

It now seems likely that if sufficiently high frequencies are allowed there is no upper bound for ground accelerations. Perhaps a more fruitful approach is to examine upper bounds for ground velocity and from them roughly estimate the acceleration levels corresponding to frequencies of structural interest. Such limiting ground velocity 
estimates can be based on impulse momentum principles applied to a simple uniform shear fault model. In this way it can be shown that maximum ground velocity should depend upon the velocity of propagation of shear waves, the shear modulus of elasticity, and the ultimate shear strength of the crustal rocks. Numerical values of these parameters are very difficult to estimate. In particular, the effective ultimate shear strength is a very uncertain factor in view of the complex roles played in the fracture process by friction, fluid pressures, and drastic modifications of the rock material in the immediate vicinity of faulting or fracture. Direct measurement of the alteration of the stress field during earthquakes had so far not been possible to attain, although meaningful approximations to the stress drops involved can now be calculated. With some reasonable guesses it appears that the limiting ground velocity could be of the order of $5 \mathrm{~m} / \mathrm{s}$ to $10 \mathrm{~m} / \mathrm{s}$. The highest ground velocity so far measured is a little over $1 \mathrm{~m} / \mathrm{s}$. This order of magnitude agreement indicates that the physical picture is probably roughly correct, but it is still not good enough for the engineer. Much more elaborate models have been suggested, but they are difficult to justify and sometimes seem to be mainly arguments for believing that the highest previously measured values are near the upper bounds. It is clear that this basic problem requires much additional work.

\section{CHARACTERISTICS OF STRONG GROUND MOTION}

In order to study in detail the characteristics of strong ground motions and to separate the effects of important variables, numerous records are needed at different sites for the same earthquake and of different earthquakes at the same site. The best example of the first situation is the 1971. San Fernando earthquake with its 241 good accelerograms, and the best example of the second situation is the accelerograph site at El Centro at which 16 different earthquakes have been recorded. Some studies based on each of these data sets will now be summarized.

In Fig. 3 are plotted all of the peak ground accelerations measured during the San Fernando earthquake. Peak acceleration is in general a parameter of dubious value which samples only the high frequency portion of the spectrum. In this case, however, since all points are from the same earthquake, some meaningful comparisons can be made. One is impressed by the great scatter of values at a given distance and by the difficulty of sorting out different site conditions. This overall picture is typical of other earthquakes for which more limited data sets have been available.

If one examines the pattern of distribution of ground shaking during an earthquake, one is usually struck by its complexity and by the difficulty of explaining even the major features. As an example Fig. 4 shows measured ground motions in a small area some distance from the San Fernando earthquake. The 19 measurements in about $100 \mathrm{~km}^{2}$ is the densest coverage so far achieved anywhere. The heavy lines have a length proportional to the response spectrum value at 0.75 seconds and 10 percent damping, and the direction is that of the maximum horizontal response. It has so far not been possible to explain the patterns in terms of simple factors such as distance from or orientation with respect to known faults, depth of alluvium, soil types, etc. A typical puzzle is that while at most stations all horizontal components are of the same magnitude in all directions, at Station SL the motions are almost unidirectional. No explanation of this in terms of geologic structure or anything else has been found.

That such distribution patterns would be expected to be very complex follows directly from a consideration of what happens to seismic waves on their way from a source region to a given site. Figure 5 illustrates the nature of this problem. Surface motions at a particular site can be influenced in a major way by surface topography, by subsurface irregularities, by the presence of various wave types such as surface waves or guided waves, by wave focussing, and by local geologic and soil conditions. A common engineering approach is to account for variations of surface motion in terms of the local soil profile. By modelling the soil as uniform horizontal layers subjected to vertically arriving shear waves, a relatively simple mathematical model is achieved which has enough parameters in it to account for almost any variation in surface motion. But the local soil environment is evidently only the last link in a long chain, including many other factors which could have an even greater effect on the surface motions than the local soils. The agreement of such simplified models with particular situations should perhaps be regarded in some cases as expressing empirical relationships, and the apparent success in some cases may even tend to conceal the real nature of the problem. To bring some of these additional factors into consideration, other types of mathematical models have recently been explored. An example is shown in Fig. 6 which shows that a simple geometric inhomogeneity in the presence of shear waves arriving at various angles can account for major variations in surface motion.

Examining next a different type of problem, it will be noted that the 16 earthquakes that have been recorded at the El Centro site can be grouped in several subsets, each containing several earthquakes. one set includes earthquakes occurring at essentially the same epicenter, and other subsets include earthquakes at various distances and azimuthal directions. This makes it possible to separate the effects of source characteristics and transmission paths from the local soil and geologic conditions which are of course the same for all records. Figure 7 shows some of the results by means of a comparison of the Fourier amplitude spectra of the recorded ground motions. The lower curves show spectra from four different earthquakes originating near the same point and thus having the same transmission path. No clearly defined peaks involving all or several of the curves are apparent, and this suggests that in this case the source mechanism is responsible for some of the significant frequency characteristics of the record. 
The upper spectra of Fig. 7 are from earthquakes having different transmission paths - here again, one notes the absence of prominent frequency peaks which could be attributed to local soil conditions. Repeated attempts have been made at the El Centro site to determine what might be called a predominant site period, using earthquake records, microtremor studies, etc., to no avail. This is a point of some significance since some earthquake codes have proposed relationships between soil factors and site periods.

As a final type of investigation based on ground motion measurements, a brute force statistical approach using all the recorded ground motions from all sites and all earthquakes can be attempted. Figures 8 and 9 show the results of one such study. Clear trends are certainly present, but the wide scatter is a disturbing reminder of the smallness of the sample and the complexity of the problem. According to one point of view, such statistical studies should be pushed forward using the best available small sample theory, with the hope that eventually some meaningful probabilistic statements will emerge. Another school of thought believes that the sample is so small and the rational physical models are so complex that such statistical statements may mean less than nothing and could even be misleading.

In conclusion it may be remarked that the difficulties alluded to above in many of the examples may be discouraging but they are probably temporary. With the recent great expansion in the number of strong motion accelerographs being installed in the world, it may be expected that in the next few years an increased number of accelerograms will help to resolve these problems. Considering the cost and difficulty of installing and maintaining suitable instrumentation, earthquake engineers are making a heavy investment in these basic strong motion seismological measurements. It is to be hoped that an equally successful effort can be applied to the interpretive problems necessary to put the results of these measurements to practical engineering use.

\section{REFERENCES}

1. Hudson, D. E., "Local Distribution of Strong Earthquake Ground Motions", Bull. Seis. Soc. Amer., Vol. 62, No. 6, December 1972.

2. Hudson, D. E., "Strong Motion Seismology", Proc. Int. Conference on Microzonation, Seattle, 1972.

3. Hudson, D. E., "Strong-Motion Earthquake Measurements in Epicentral Regions", Proc. Sixth World Conference on Earthquake Engineering, New Delhi, 1977.

4. Hudson, D. E., "Reliability of Records - Panel 1, Earthquakes", Proc. Sixth World Conference on Earthquake Engineering, New Delhi, 1977.

5. Trifunac, M. D., "Surface Motion of a Semi-Cylindrical Alluvial Valley for Incident Plane SH Waves", Bull. Seis. Soc. Amer., Vol. 61, No. 6, December 1971.

6. Trifunac, M. D., and Brady, A. G., "On the Correlation of Seismic Intensity Scales with the Peaks of Recorded
Strong Ground Motion", Bull. Seism. Soc. Amer., Vol. 65, No. 1, February 1977.

7. Trifunac, M. D., "Preliminary Empirical Model for Scalina Fourier Amplitude Spectra of Strong Ground Motion in Terms of Earthquake Maqnitude, Source to Station Distance, and Recording Site Conditions", Bull. Seism. Soc. Amer., Vol. 66, No. 4, August, 1976.

8. Udwadia, F. E., Investigation of Earthquake and Microtremor Ground Motions, Report EERL 72-02, Earthquake Engineering Research Laboratory, California Institute of Technology, 1972 .

Paper received 17 August, 1977. 

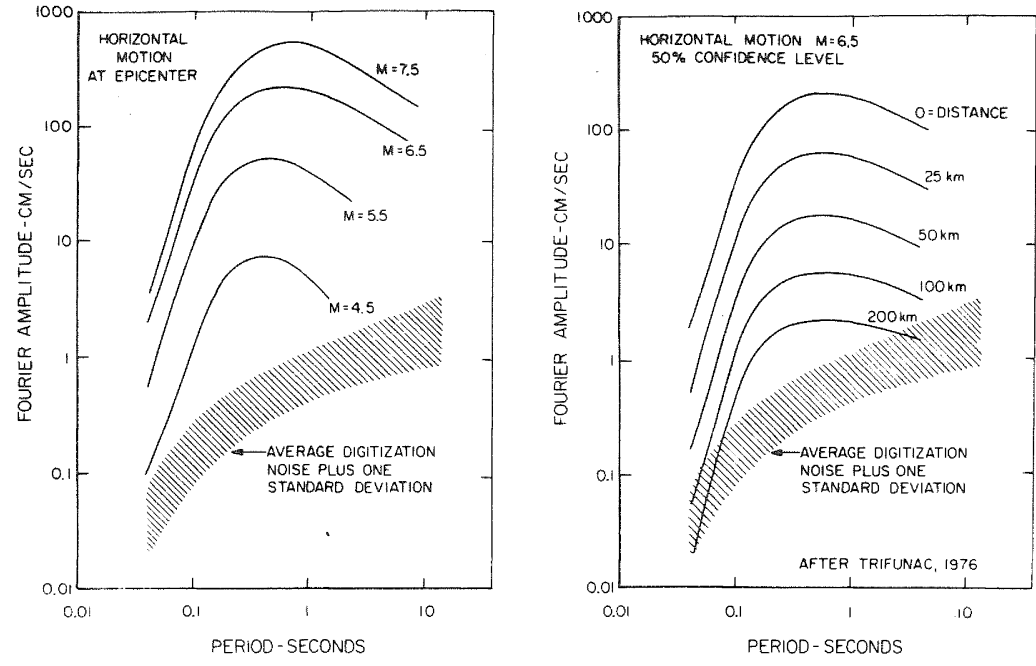

FIGURE 1: NOISE CHARACTERISTICS OF THE STANDARD U.S. STRONG MOTION ACCELEROGRAPH SYSTEM (REFS. 4,7 )

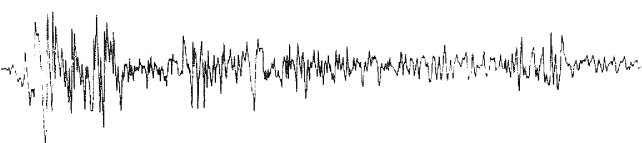

EL CENTRO $1940-$ SOUTH

M 6.7

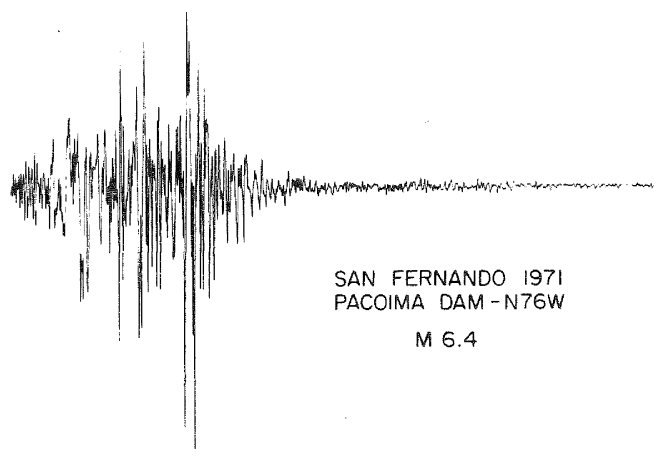

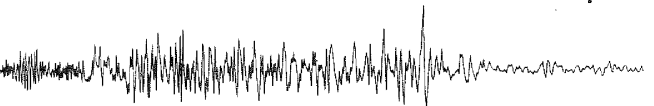

OLYMPIA $1949-$ N86E M 7.1
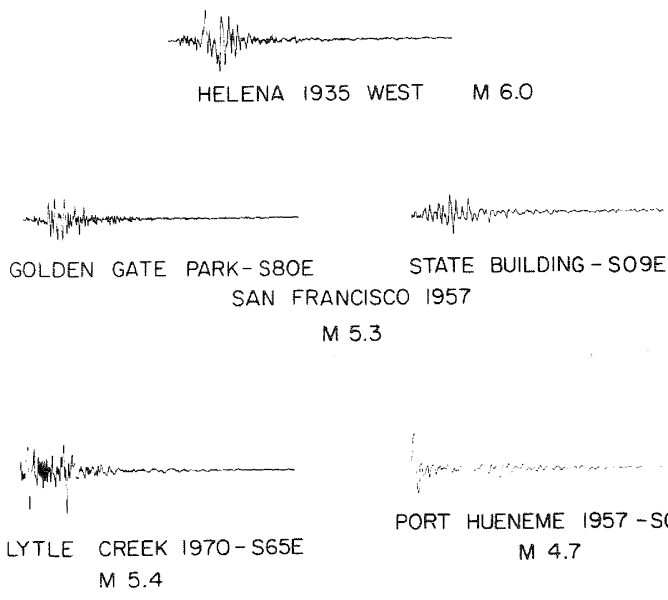

PORT HUENEME 1957 -SOUTH M 4.7
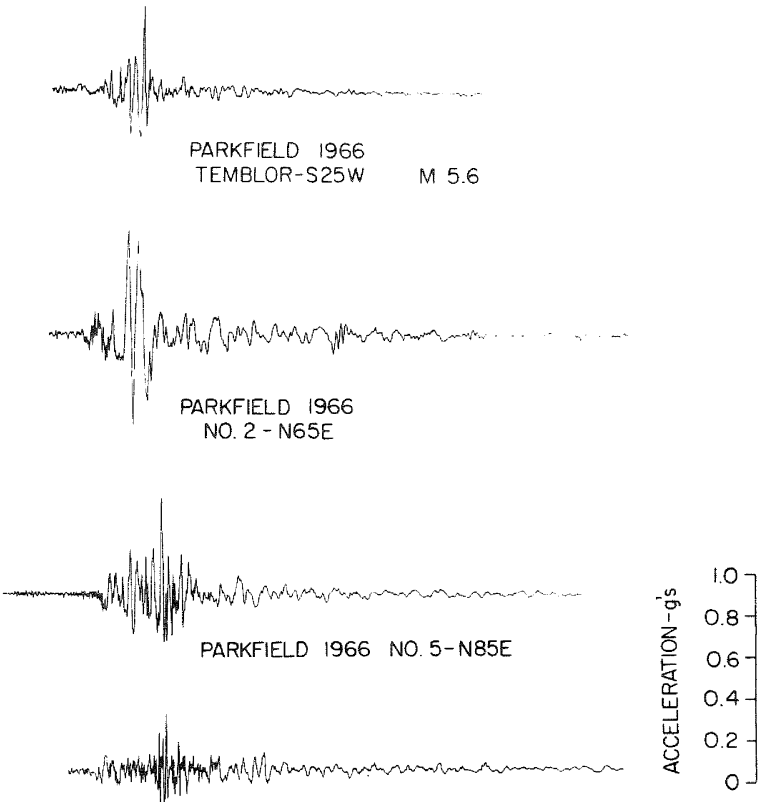

PARKFIELD 1966 NO. 8-N5OE
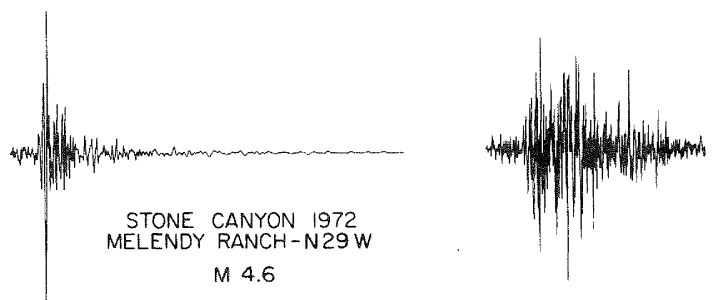

KOYNA 1967-LONG M 6.5

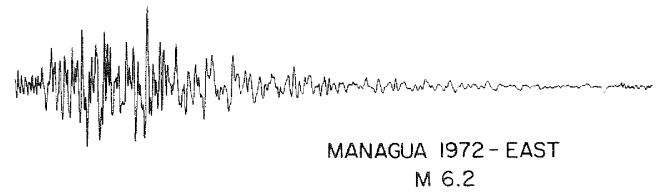

$\begin{array}{lllllll}0 & 5 & 10 & 15 & 20 & 25 & 30\end{array}$

TIME - SECONDS 

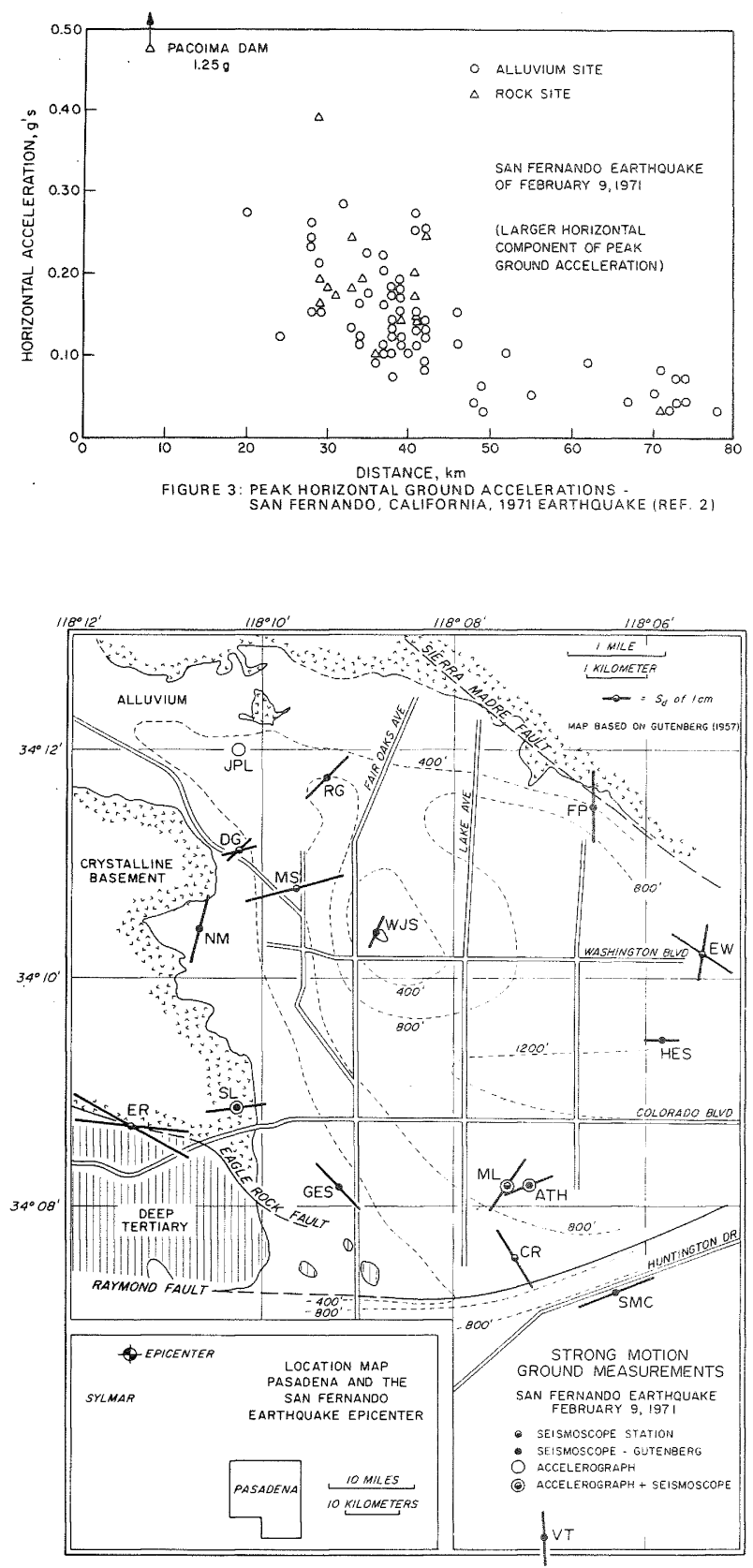

FIGURE 4: DISTRIBUTION OF STRONG GROUND MOTION MEASUREMENTS IN PASADENA AREA - SAN FERNANDO, CALIFORNIA, 1971 EARTHOUAKE (REF. 1)
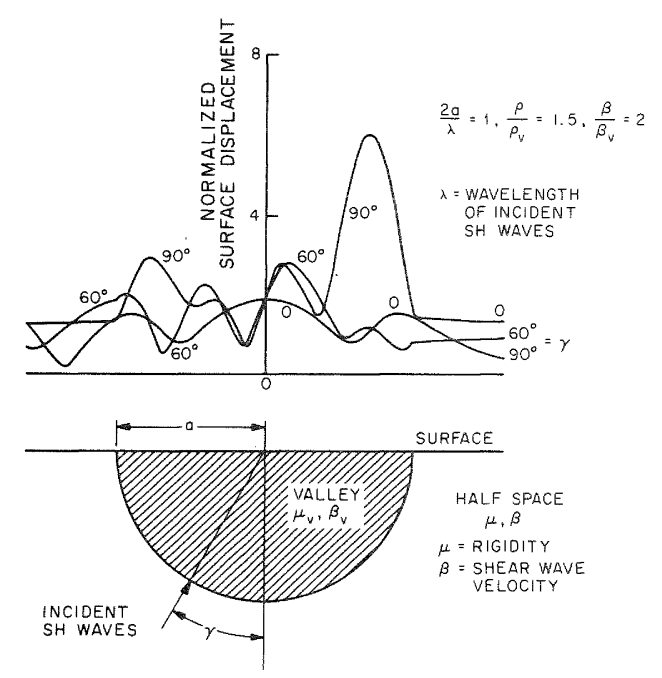

FIGURE 6: SURFACE MOTION OF A SEMI-CYLINDRICAL

ALLUVIAL VALLEY FOR INCIDENT SHEAR WAVES (REF, 5)

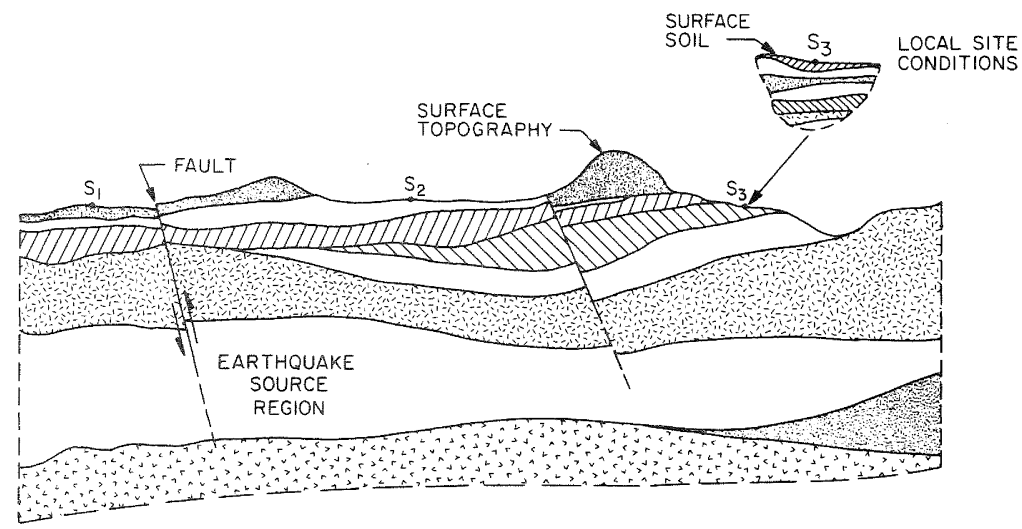

FIGURE 5: SCHEMATIC DIAGRAM SHOWING EARTHQUAKE SOURCE REGION, TRANSMISSION PATH, AND LOCAL SITE CONDITIONS (REF. 8 )
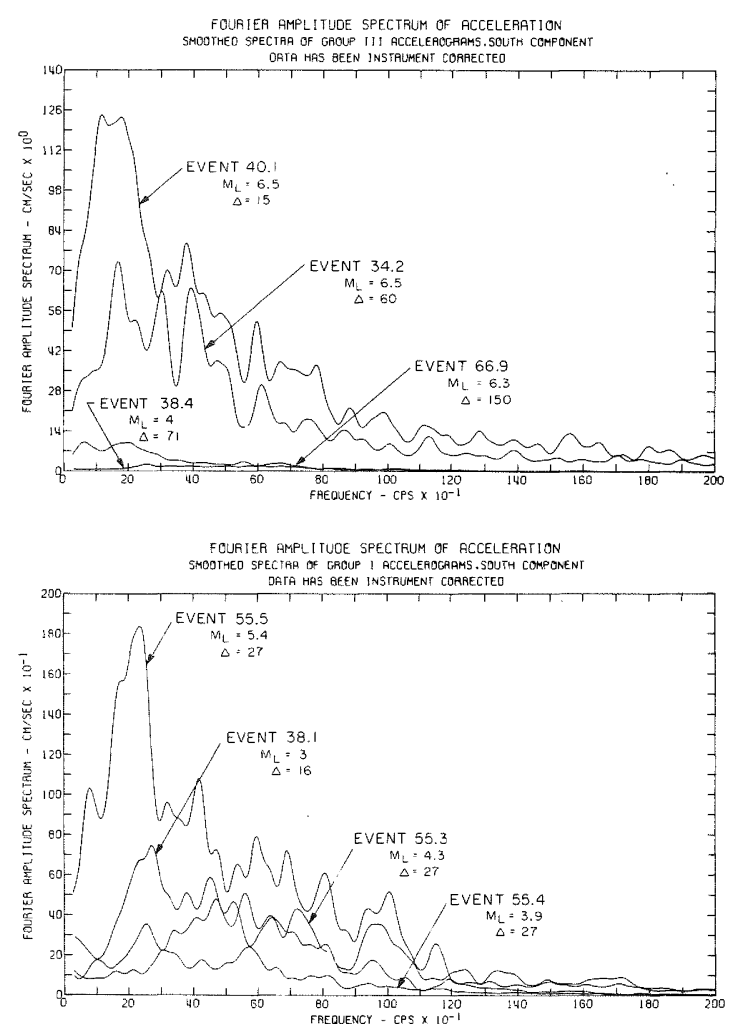

FIGURE 7: SMOOTHED FOURIER AMPLITUDE SPECTRA OF ACCELEROGRAMS AT THE EL CENTRO, CALIFORNIA, SITE (REF. 8) 

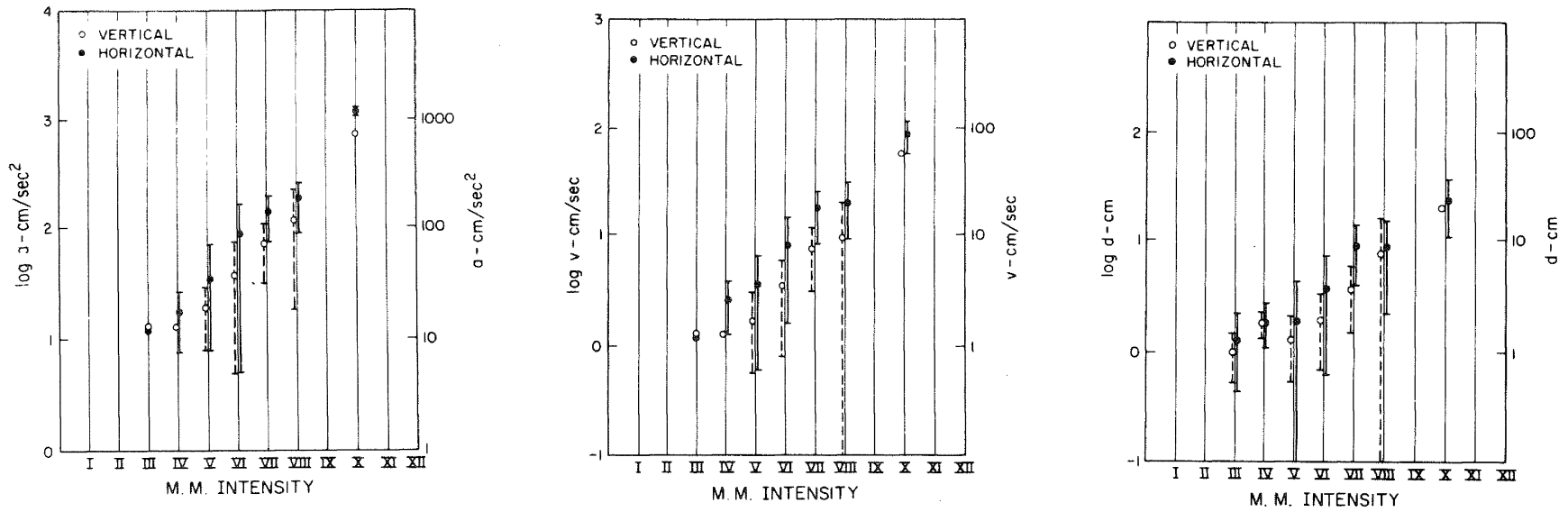

FIGURE 8: CORRELATION OF PEAK GROUND MOTIONS

WITH MODIFIED MERCALLI INTENSITIES (REF. 6)
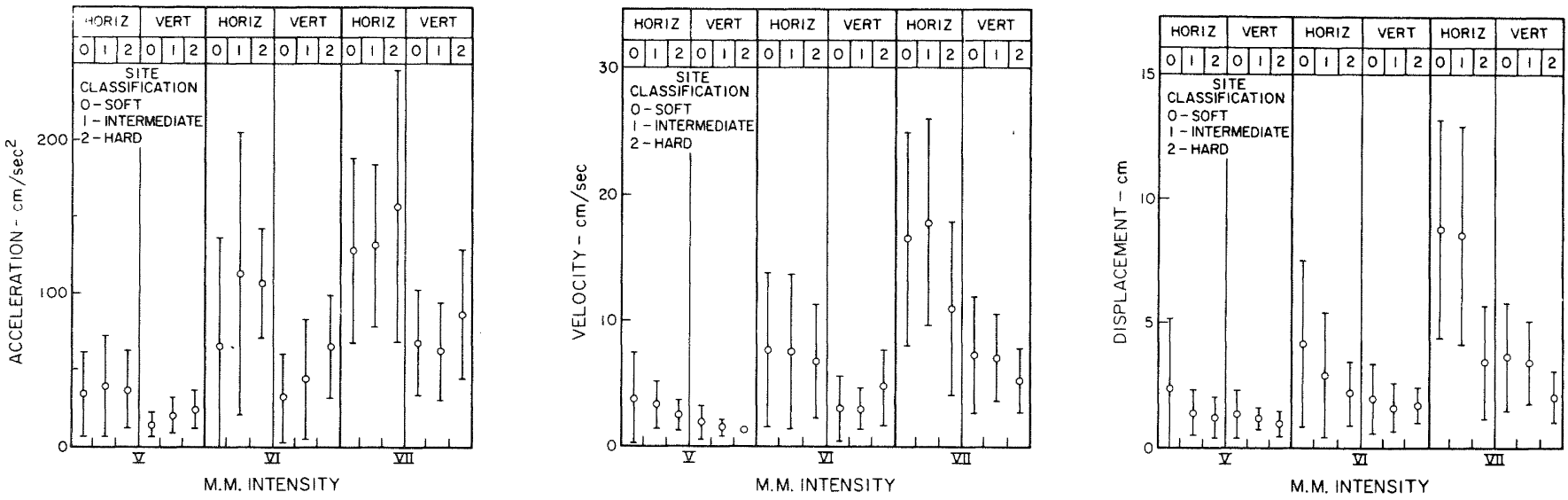

FIGURE 9: CORRELATION OF PEAK GROUND MOTION

WITH INTENSITIES AND SITE CONDITIONS (REF. 6) 